\title{
Age-based and reproductive biology of the Pacific Longnose Parrotfish Hipposcarus longiceps from Guam
}

\author{
Brett M Taylor ${ }^{\text {Corresp., }} 1$, Eric Cruz ${ }^{2}$ \\ 1 Joint Institute for Marine and Atmospheric Research, University of Hawaii, Honolulu, HI, United States \\ 2 Guam Field Office, NOAA Pacific Islands Fisheries Science Center, Barrigada, Guam, United States \\ Corresponding Author: Brett M Taylor \\ Email address: brett.taylor@noaa.gov
}

The Pacific longnose parrotfish Hipposcarus longiceps (Valenciennes 1840) represents a prime fishery resource throughout much of the tropical Pacific. In this study, we sampled the species from the Guam commercial fishery market across 5 consecutive years to characterize reproductive and age-based demographic information imperative for informed fishery management. Compared with other parrotfishes, this species was found to be large-bodied, but has only a moderate life span of 10+ years. Hipposcarus longiceps was confirmed as a diandric protogynous hermaphrodite with highly sex-specific growth patterns and an overall mean asymptotic length of $434 \mathrm{~mm}$ fork length (FL). Females were estimated to reach median maturity at $329 \mathrm{~mm}$ FL (2.4 years) and have a median length at female-to-male sex change of $401 \mathrm{~mm}$ FL. Life-history trait values derived here were used to update previous models relating life history and vulnerability to overexploitation. We found that enhancement of just one species' trait values improved model fits considerably, which strengthens the conclusion that life-history traits are a strong determinant of species' vulnerability in the parrotfishes. This information is an imperative complement to other data sources facilitating formal stock assessment of a key fishery target. 
1

2

3

4

5

7

8

9

10

11
Age-based and reproductive biology of the Pacific Longnose Parrotfish Hipposcarus longiceps from Guam

Brett M. Taylor*1, Eric Cruz ${ }^{2}$

${ }^{1}$ Joint Institute for Marine and Atmospheric Research, University of Hawaii and NOAA Fisheries, Pacific Islands Fisheries Science Center, Honolulu, HI, United States of America ${ }^{2}$ NOAA Fisheries, Pacific Islands Fisheries Science Center, Guam Field Office, Barrigada, Guam, United States of America

*Corresponding author. Email: brett.taylor@noaa.gov

Phone: +1 (808) 725-5606 


\section{Abstract}

13 The Pacific longnose parrotfish Hipposcarus longiceps (Valenciennes 1840) represents a prime

14 fishery resource throughout much of the tropical Pacific. In this study, we sampled the species

15 from the Guam commercial fishery market across 5 consecutive years to characterize

16 reproductive and age-based demographic information imperative for informed fishery

17 management. Compared with other parrotfishes, this species was found to be large-bodied, but

18 has only a moderate life span of 10+ years. Hipposcarus longiceps was confirmed as a diandric

19 protogynous hermaphrodite with highly sex-specific growth patterns and an overall mean

20 asymptotic length of $434 \mathrm{~mm}$ fork length (FL). Females were estimated to reach median maturity

21 at $329 \mathrm{~mm}$ FL (2.4 years) and have a median length at female-to-male sex change of $401 \mathrm{~mm}$ FL.

22 Life-history trait values derived here were used to update previous models relating life history

23 and vulnerability to overexploitation. We found that enhancement of just one species' trait values

24 improved model fits considerably, which strengthens the conclusion that life-history traits are a

25 strong determinant of species' vulnerability in the parrotfishes. This information is an imperative

26 complement to other data sources facilitating formal stock assessment of a key fishery target. 


\section{Introduction}

Parrotfishes (family Labridae; tribe Scarinae) are among the most common groups of taxa represented in coastal fisheries harvests of the tropical Indo-Pacific region (Rhodes, Tupper \& Wichilmel, 2008; Taylor \& Choat, 2014). At the U.S. Pacific Island Territory of Guam, parrotfishes (known collectively in native Chamorro as palaksi or laggua based on body phase coloration; Kerr, 1990) have been important fishery resources in both historical and contemporary times (Houk et al., 2012). Overall, parrotfishes represent approximately $20 \%$ of the total Guam nearshore commercial harvest by weight, making them the second most common taxonomic group (NOAA Commercial Fisheries BioSampling Program, unpublished data). Since the 1980s, nighttime spearfishing with the aid of SCUBA has been the most prevalent means of harvesting reef-associated species commercially, with parrotfishes being particularly susceptible to this method because of their behavior of sleeping in easily located habitats on coral reefs.

Among the $20+$ parrotfish species that occur at Guam, the most heavily targeted species by weight is Hipposcarus longiceps (native Chamorro name gualafi). This species is also the third most targeted species by weight in the SCUBA-spear fishery, behind the unicornfishes Naso unicornis (Forsskål 1775) and N. lituratus (Forster 1801). Hipposcarus longiceps is phylogenetically unique (only two extant Hipposcarus exist; Choat et al., 2012), forms large schools for both foraging and reproduction (Colin, 2012), and is one of the largest species of parrotfish that occurs at Guam, sometimes reaching nearly $60 \mathrm{~cm}$ fork length. H. longiceps is considered a scraping detritivore and microphage (Bellwood \& Choat, 1990; Choat, Robbins \& Clements, 2004), and is most commonly found in schools roving back and forth across the fore reef environments adjacent to reef flats or lagoons on Guam (Taylor et al., 2014). The species can be found sleeping in schools, sporadically spaced across the reef within a relatively small 
51 area (B. Taylor, pers. obs.), and are thus behaviorally predisposed to be prime targets to

52 nighttime spear fishers. As with many scarine labrids, H. longiceps adults have two distinct,

53 albeit subtly different, color phases (initial and terminal) reflecting female and male sexes (see

54 Colin, 2012), except that primary males (individuals that originally developed as males) are

55 found in both color phases. Terminal phase primary males have undergone metamorphosis of

56 body coloration during their ontogeny without changing sex, as can be confirmed histologically

57 (Taylor \& Choat 2014).

Life-history traits are known to strongly influence species' responses to exploitation

59 (Adams, 1980; Abesamis et al., 2014). This relationship between vulnerability to

60

61

62

63

64

overexploitation and life-history trait values has been well-documented in the parrotfishes, specifically across reefs of Guam (Taylor et al., 2014), whereby age at female maturation was the strongest predictor of spatial and temporal patterns of fishery-induced demographic changes across species. In that analysis, $H$. longiceps was found to be among the most vulnerable species with corresponding life-history traits (e.g., length and age at maturity, length at sex change, maximum length, growth rate, maximum age) generally achieving higher values compared with other species. However, that study incorporated life-history data from Pohnpei (Federated States of Micronesia) as a proxy for Guam H. longiceps. Life-history traits can vary considerably and predictably within regions, whereby we would expect Guam populations to be larger-bodied and potentially longer-lived based on island geomorphology and latitude (Taylor, 2014).

The purpose of this study is to derive detailed age-based and reproductive demographic information for the most commonly targeted parrotfish species in Guam's commercial fishery. This study provides initial insight to stock status, facilitates future formal stock assessment, and updates models of vulnerability to better reflect locally-specific parameter values. Market-based 
74 surveys and collections spanning nearly 6 years were undertaken to derive parameters of growth,

75 life span, reproductive ontogeny, mortality, and spawning periodicity.

76

77 Materials \& Methods

78

79

80

81

82

83

84

85

86

87

88

93

94

95 96

Study area and sampling protocol

The major commercial vendor of reef-associated fisheries was surveyed on the U.S.

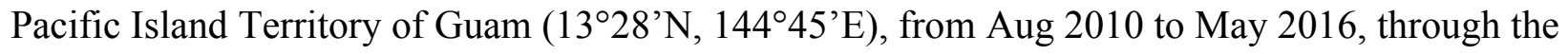
NOAA Commercial Fisheries BioSampling Program (CFBP). All research was carried out under permit UOG1202 issued by the University of Guam Institutional Animal Care and Use

Committee. Survey methods and sampling protocols are detailed in Sundberg et al. (2015). An average of 5 specimens of Hipposcarus longiceps was purchased monthly for biological analysis. Specimens were processed immediately after purchasing. For each specimen, general location of capture and fishing method were obtained from the vendor; measurements of fork length (FL, nearest $\mathrm{mm}$ ) and total body weight (TW, g) were also obtained. Sagittal otoliths and gonad lobes were surgically removed from each specimen for subsequent processing. Otoliths were cleaned in ethanol and stored dry in plastic vials. Gonad lobes were weighed to the nearest $0.001 \mathrm{~g}(\mathrm{GW})$. Entire gonads or sections $(1 \mathrm{~cm}$ thick) of gonad material from the mid-sections of gonad lobes were removed and stored using individually-labelled histological cassettes in a buffered 10\% formalin solution or Shandon ${ }^{\circledR}$ Glyofix ${ }^{\circledR}$.

Age determination and growth

One sagittal otolith from each specimen's pair was randomly selected for age analysis. Each otolith was affixed to a glass slide using thermoplastic glue (Crystalbond $509^{\circledR}$ ) so that the 
97 primordium was focused just inside the slide edge, and the direction of the sulcus ridge was

98 perpendicular to the slide edge. The otolith was ground to the primordium using a 600 grit diamond lap on a grinding wheel along the longitudinal axis to the edge of the slide. The otolith was then removed using a hotplate and reaffixed with the newly flat surface down and ground to produce a thin $(\sim 250 \mu \mathrm{m})$ transverse section encompassing the core material. Annuli (alternating translucent and opaque bands) along the face of the transverse sections were counted using transmitted light on a stereo microscope on three separate occasions. Annual ages were assigned when at least two counts were in agreement, which occurred for all but four specimens. Counts 105 of those four specimens differed by only 1 annuli (e.g., 9, 11, 10), so the middle value (e.g., 10) was assigned. scored as opaque (slower growth, denser material) or translucent (faster growth, less-dense material). Decimal ages (fish ages to a finer resolution than one year) were not derived because the species spawns and presumably recruits throughout the year; hence, there is no appropriate mean birth date for specimens.

fitted with the von Bertalanffy growth function (VBGF), represented by:

$$
L_{t}=L_{\infty}\left[1-e^{-k\left(t-t_{0}\right)}\right]
$$

where $L_{t}$ is the predicted mean FL (mm) at age $t$ (years), $L_{\infty}$ is the asymptotic FL, $k$ is the

117 coefficient used to describe the curvature of fish growth towards $L_{\infty}$, and $t_{0}$ is the hypothetical

118 age at which FL is equal to zero, as described by $k$. The growth model was constrained to a common FL at settlement of $15 \mathrm{~mm}$ (following Bellwood \& Choat, 1989) to account for early 
120 growth of juveniles since specimens below $195 \mathrm{~mm}$ FL were not obtained. Male and female

121 growth patterns were compared by plotting 95\% bivariate confidence ellipses surrounding paired

122 estimates of $L_{\infty}$ and $k$ following Kimura (1980).

124 Mortality

125 Age composition and instantaneous rates of mortality were explored through age

126 frequency distributions. The sex-specific frequency of individuals sampled from the fishery was

127 plotted by length and age classes. The instantaneous rate of total mortality $\left(Z, \mathrm{yr}^{-1}\right)$ was

128 estimated two ways. First, we used a Gaussian likelihood-based linear catch curve with knife-

129 edge selectivity. This method estimated $Z$ as the absolute value of the slope of a line fitted to the

130 natural logarithm of observed frequency of harvested individuals at age $t\left(O_{t}\right)$ for corresponding

131 age classes above $t_{c}$, the age at which fish are assumed fully recruited into the fishery (Beverton

$132 \&$ Holt, 1957). We conservatively defined $t_{c}$ as one plus the age at peak observed frequency.

133 We then used a multinomial likelihood-based catch curve using logistic selectivity by

134 minimizing the multinomial negative $\log$-likelihood $\lambda$ associated with $O_{t}$ and the expected

135 proportion $\left(P_{t}\right)$ of fish at or above $t_{c}$

136

$$
\lambda=-\sum_{t=1}^{A} o_{t} \ln \left(P_{t}\right)
$$

137

$$
P_{t}=\frac{C_{t}}{\sum_{t=1}^{A} C_{t}}
$$


138 Where $A$ refers to the maximum age assumed in the analysis, arbitrarily set much larger than 139 the observed maximum age, thereby avoiding calculation of a "plus group." $C_{t}$ is the expected 140 catch at age $t$, calculated using the Baranov catch equation:

$$
C_{t}=\frac{F_{t}}{Z_{t}} N_{t}\left(1-e^{-Z_{t}}\right)
$$

$$
Z_{t}=F_{t}+M
$$

$$
F_{t}=F V_{t}
$$

$$
V_{t}=\frac{1}{1+e^{\frac{-\ln (19)\left(t-A_{50}\right)}{\left(A_{95}-A_{50}\right)}}}
$$

145 where $F_{t}$ is the fishing mortality at age $t, F$ is the "full" instantaneous fishing mortality, and $146 V_{t}$ is the estimated gear selectivity at age $t$ following a logistic function with selectivity 147 parameters $A_{50}$ and $A_{95}$, the ages at $50 \%$ and $95 \%$ selectivity, respectively. The equation of 148 Hoenig (1983) was used to estimate natural mortality $(M)$ based on the maximum observed

$$
Z=e^{\left(1.46-1.01 * \ln \left(\mathrm{t}_{\max }\right)\right)}
$$

Reproduction at the University of Hawaii. Fixed sections of gonad tissue were imbedded with paraffin wax, sectioned transversely at $6 \mu \mathrm{m}$, and stained on microscope slides with haematoxylin and eosin 
157 following standard procedures. Samples were viewed under compound and stereo microscopes to

158 identify features determining sex and maturation stage following criteria detailed in West (1990)

159 and using standardized terminology from Brown-Peterson et al. (2011). Particular attention was

160 given to (1) presence or absence of post-ovulatory follicles (POFs) as confirmation of prior

161 spawning, (2) proof of post-maturational sex change in the form of proliferating spermatogenic

162 material in the presence of degenerative vitellogenic oocytes, and (3) characteristics of an

163 ovarian lumen in male testes signifying secondary (prior sex change from female to male) versus

164 primary (individual originally developed as male) male development.

Length (mm, FL) and age (years) at 50\% female maturation and sex change were

estimated by fitting a two-parameter logistic curve to the proportion of mature individuals per

length and age class (20 $\mathrm{mm}$ and 1-year bins). The logistic curve was as follows: $P_{L}=$

$168\left[1+e^{-\ln (19)\left(L-L_{50}\right) /\left(L_{95}-L_{50}\right)}\right]^{-1}$, where $P_{L}\left(P_{t}\right.$ for age at maturity) represents the estimated

169 proportion of mature females at a given length $(L)$, and $L_{50}$ and $L_{95}\left(t_{50}\right.$ and $t_{95}$ for age at

170

171

172

173

174

175

176

177

178

179 maturity) represent the FL when $50 \%$ and $95 \%$ of the population is reproductively mature. The same procedure was carried out to estimate length at sex change, where lengths at $50 \%$ and $95 \%$ sex change are denoted by $L_{\Delta 50}$ and $L_{\Delta 95}$. Corresponding $95 \%$ confidence intervals $(\mathrm{CI})$ for each parameter were derived by bootstrap resampling using 1000 iterations.

A gonadosomatic index (GSI) was calculated as the ratio of gonad-to-gonad-free body weight for each mature female in an active (not resting or spent) phase. We then examined temporal trends in GSI across calendar months and lunar days by plotting raw GSI values pooled across these timeframes. Occurrence of POFs or hydrated oocytes was also examined across these timeframes to indicate timing and frequency of spawning activity at two temporal scales. 
180

181

182

183

184

185

186

187

188

189

190

191

192

193

194

195

196

197

198

199

200

201

202

\section{Re-examination of vulnerability to overexploitation}

The influence of life-history traits on the incidence and magnitude of vulnerability to overexploitation was examined for Guam parrotfishes in Taylor et al. (2014), using patterns of abundance and mean length across spatial and temporal gradients of fishing pressure. $H$.

longiceps was found to be among the more vulnerable species in the Guam assemblage, but lifehistory trait values assessed in that study were derived from a surrogate location of Pohnpei, Micronesia. Patterns of life-history variation associated with geomorphological differences between Guam and Pohnpei suggest that Guam H. longiceps would be larger and longer-lived (Taylor, 2014). Hence, we repeated the prior analyses of incidence and magnitude of vulnerability by replacing the Pohnpei $H$. longiceps data with newly derived Guam data from the present study. Specifically, the traits age at maturity $\left(t_{50}\right)$, length at female maturity $\left(L_{50}\right)$, length at sex change $\left(L_{\Delta 50}\right)$, mean maximum length and age (mean of the largest $\left[L_{\max }\right]$ and oldest $\left[t_{\max }\right]$ quartile of the sampled population), and modeled growth (in mm) from age 1 to age $3\left(L_{1-3}\right)$ were assessed for their power to predict vulnerability to overexploitation across species (details of analysis in Taylor et al., 2014). We hypothesized that model fits would improve with the use of regional-specific Guam data in lieu of population parameters from Pohnpei.

\section{Results}

Age determination and growth

From Dec. 2009 to May 2016, a total of 3,369 individual H. longiceps were surveyed from the Guam commercial fishery. Ninety-seven percent of these were harvested by spearfishing with SCUBA, $1.6 \%$ by spearfishing with snorkel, and $1.4 \%$ by gill net or unknown method(s). From these, 330 were purchased and sampled for life-history analysis. The smallest 
203 and largest specimens sampled were $188 \mathrm{~mm}(130 \mathrm{~g})$ and $514 \mathrm{~mm}$ FL (2,650 g), respectively,

204 and the average length and weight of sampled fish was $366 \mathrm{~mm} \mathrm{FL} \mathrm{(} \pm 75 \mathrm{SD})$ and $1073 \mathrm{~g}( \pm 593$

205 SD). The relationship between FL (mm) and TW (g) was described by $T W=1.739 \times 10^{-5}$

$206(F L)^{3.018}$ (earlier derivation of this relationship for cm presented in Kamikawa et al., 2015).

207 Transverse sections of sagittal otoliths revealed overall banding patterns that were highly

208 consistent in deposition among specimens (Fig. 1). These bands were confirmed to be annular by

209 edge-type analysis, whereby opaque zones, representing slow growth, were deposited in the

210 winter months (peaked in December) and were non-existent at the otolith edge from April to July

211 (Fig. 1). Spacing of the first increment was variable among specimens because individuals likely

212 recruited throughout the year (see Reproduction section). Because of this, individual ages

213 throughout are reported in years as integers, representing the total number of annular bands.

214 Sampled female $H$. longiceps ranged from 195 to $470 \mathrm{~mm}$ FL (mean $=345 \mathrm{~mm} \pm 57 \mathrm{SD}$ ),

215 and sampled males ranged from 242 to $514 \mathrm{~mm}$ FL (mean $=416 \mathrm{~mm} \pm 59$ SD; Fig. 2a). Sex-

216 specific length ranges overlapped considerably but frequency distributions demonstrated that

217 males were, on average, much larger than females (two sample $\mathrm{t}$-test, $\mathrm{df}=300, \mathrm{t}=-10.66, \mathrm{P}<$

218 0.001). Primary males (based on histological features of testis; represents both IP and TP primary

219 males) spanned the full size range of all males. The modal age for females was two years, and

220 proportional frequencies dropped drastically beyond that age group (mean age $=2.8$ years). For

221 males, the modal age ranged from 2-5 years for which there was approximately equal

222 frequencies (mean age $=4.0$ years). Males were generally older than females, and the oldest

223 individuals collected for each sex were ten years for males and nine years for females (Fig. 2b).

224 Seven of the aged specimens were considered sex unknown, for which macroscopic designations

225 were undetermined, and no histology was performed. 
227 total mortality $(Z)$ based on the linear age-based catch curve with knife-edge selectivity was

228

229

230

231

232

233

234

235

236

237

238

239

240

241

242

243

244

245

246

247

248

$0.476 \mathrm{yr}^{-1}(0.375-0.57795 \% \mathrm{CI})$, and the $Z$ estimate from the multinomial catch curve was 0.402 $\mathrm{yr}^{-1}\left(0.287-0.51895 \%\right.$ CI) (Fig. 2b). Hoenig's (1983) estimate of $M$ was $0.421 \mathrm{yr}^{-1}$, presuming the maximum age of 10 years represents the natural maximum age in the unexploited wild population. This value was greater than the multinomial catch curve estimate of $Z$, suggesting that estimates of $Z$ and $M$ from the fishery-dependent samples are not robust.

Overall, H. longiceps grew rapidly in the first year, achieving over $300 \mathrm{~mm}$ in many specimens with one annuli (Fig. 3). The general asymptotic length was reached in year four, whereas growth profiles separated for the males and females at year three. Males reached a mean asymptotic length of $466 \mathrm{~mm}$ FL, whereas females reached $396 \mathrm{~mm}$ FL. Sex-specific growth profiles differed considerably, as shown by non-overlapping bivariate confidence ellipses surrounding estimates of $L_{\infty}$ and $K$ (Fig. 3). The overall growth parameters (sexes combined) for H. longiceps in Guam were $L_{\infty}=434 \mathrm{~mm} \mathrm{FL,} K=0.786 \mathrm{yr}^{-1}$, and $t_{0}=-0.045$ years (Table 1 ).

\section{Reproduction}

A total of 270 specimen gonads were processed histologically for assignment of sex and reproductive stages. These individuals ranged from 195 to $514 \mathrm{~mm} \mathrm{FL}$ and included 150 females and 120 males. Three of the males were considered to be in the process of sexual transition from female to male and displayed degenerative oocytes in the presence of proliferating spermatogenic material (Fig. 4). Macroscopic field designations of sex were accurate $80 \%$ of the time. The length and age at 50\% female maturation was found to be $329 \mathrm{~mm}$ FL (313-345, 95\% CI) and 2.4 years $(2.2-2.7,95 \% \mathrm{CI})$, respectively (Fig. 5a,b). Length at sex change was 
249 determined to be $401 \mathrm{~mm}$ FL (381-420, 95\% CI; Fig. 5c). Age at sex change was not calculable

250 because sex change is a highly length-based, socially-mediated process, whereby many females

251 do not undergo sex change throughout extended life spans.

252 We found few insights to spawning periodicity or frequency across calendar months or

253 lunar phases. Mature, active females had GSI values up to 4\% of their gonad-free body weight

254 (Fig. 6). We found no annual or lunar trend in GSI values, and we found a high proportion of

255 mature, active females containing post ovulatory follicles and/or hydrated oocytes in every

256 calendar month and across each lunar phase (Fig. 6). The proportional presence of POFs and

257 hydrated oocytes appears to correlate with the maximum observed GSI across both annual and

258 lunar timescales.

259

260

\section{Vulnerability analyses}

261

Trait values for Guam $H$. longiceps were greater than those from Pohnpei for five of the

262 six life-history traits examined in vulnerability models, based on Taylor et al. (2014). As

263 predicted, a majority (ten out of twelve) of models examining the predictive power of life-history

264 traits on vulnerability to overexploitation had an improved fit with the substitution of Guam $H$.

265 longiceps data (Supplementary material). Only the predictive power of age at maturity $\left(t_{50}\right)$

266 decreased, although this trait remained the most influential for explaining incidence of response.

267 Overall, the average variance explained increased by $4 \%\left(6 \%\right.$ without $\left.t_{50}\right)$ for models predicting

268 incidence of response and by $6.5 \%\left(11 \%\right.$ without $\left.t_{50}\right)$ for models predicting magnitude of

269 response (Supplementary material).

270

271 Discussion 
This study provides the most comprehensive assessment of age-based and reproductive

273 biology for Hipposcarus longiceps, a species that is commonly harvested in reef-associated

274 subsistence and commercial fisheries throughout the tropical Pacific. In brief, H. longiceps is a

275 comparatively large-bodied parrotfish with a moderate life span and fairly rapid initial growth to

276 targeted size classes. We found no evidence of distinct reproductive periodicity at any temporal

277 scale, but did identify several features of reproductive demography considered unique among the

278 parrotfishes. Below, we discuss our findings in a phylogenetic, behavioral, and fisheries context.

Our results provide the first confirmatory evidence of functional diandric protogynous

sex change in the genus Hipposcarus, based on histological examination of gonad structures and

sex-specific size and age distributions. This result is not surprising, given that protogynous

hermaphroditism dominates among the parrotfishes. However, H. longiceps is phylogenetically

distinct, and confusion over reproductive function in scarine labrids is not uncommon (Sadovy

de Mitcheson \& Liu, 2008); examples of functional gonochorism exist (Robertson, Reinboth, \&

Bruce, 1982; Hamilton, Adams, \& Choat, 2008). Another peculiar feature of the reproductive

(present study) were initial phase primary males. The presence and proportion of initial phase with increased social group size (Munday, White, \& Warner, 2006). Observed differences between populations may reflect lower densities in Guam compared with Pohnpei, although this cannot be resolved at present. However, this has been observed for subpopulations on the Great 
295

296

297

298

299

300

301

302

303

304

305

306

307

308

309

310

311

312

313

314

315

316

317

spilurus (Valenciennes 1840) (formerly Chlorurus sordidus [Forsskål 1775]) contained greater proportions of primary males (Gust, 2004).

Despite sampling across all calendar months over a 5+ year period, our data resolution was not great enough to derive insight to spawning periodicity for $H$. longiceps, either on an annual or a lunar time scale, based on GSI patterns. However, there was a very high proportion of mature females with post-ovulatory follicles and/or hydrated oocytes across all months (mean $=75 \%$ ) and lunar periods (mean $=78 \%$ ), suggesting that spawning activity occurred frequently throughout each year. Detailed descriptions of spawning behavior have been documented by Colin \& Bell (1991) from Enewetak Atoll in the Marshall Islands and by Colin (2012) from Palau. In both accounts, groups were observed spawning at seaward facing reefs after high tide, often following the full or new moon lunar phases. Males appear to patrol territories and engage in courtship behavior. Both of these locations where spawning has been observed are geomorphologically different from Guam, and reef morphology can strongly influence reproductive behavior in labrids (Warner \& Hoffman, 1980). However, the level to which the reproductive ecology of $H$. longiceps in Guam may reflect or differ from that previously reported from elsewhere remains unclear.

The present study also provides the first validation of annual periodicity in otolith increments of Hipposcarus using edge-type analysis. Maximum age from 279 specimens was found to be 10 years on Guam. Other maximum age estimates from $H$. longiceps are 6 years from Pohnpei (Taylor \& Choat, 2014) based on 65 specimens, 12 years from the northern Great Barrier Reef (Choat \& Robertson, 2002) based on 23 specimens, and 5 years from Solomon Islands (Sabetian, 2010) based on 67 specimens. It is now clear that H. longiceps, while among the larger parrotfishes, has only a moderate life span potentially stretching into the low teens and 
318 naturally varying across environments, latitude, and different fishing pressures. Both males and

319 females were well-represented in the older age classes, suggesting that sex change is a largely

320 length-based, socially-mediated process and many older females never undergo sex change

321 through their life spans.

322 We found poor compatibility among mortality estimates in this study. The estimate of

323 natural mortality from the Hoenig (1983) equation exceeded the estimate of total mortality from

324 the more robust multinomial catch curve, implying that the species on Guam faces no fishing

325 pressure. This does not conform with two facts: (1) H. longiceps is among the most prevalently

326 harvested species in the commercial fishery, and (2) mean harvested length has declined steadily

327 over at least a 30-year period (Lindfield et al., 2014; NOAA CFBP, unpublished data). We

328 suspect discrepancies arise for two reasons. First, the dynamics of the fishery may make

329 estimating total mortality from fishery-dependent data challenging. The night-time harvest of $H$.

330 longiceps is highly seasonal. The period of greatest harvest coincides with the calmest ocean

331 conditions, approximately from May through August, where average monthly harvest weight

332 more than doubles. Further, the inherent nature of the spear-fishery is highly selective, and larger

333 individuals are preferred based on market value. Sampling was also not conducted over a

334 discrete time period, allowing potential fluctuations in annual recruitment to influence catch

335 curve estimates. A fishery-independent sampling strategy may rectify some of these issues and

336 improve resolution for instantaneous mortality rates. Secondly, our age estimates possibly

337 underestimated true maximum age, thereby increasing our estimate of natural mortality. The

338 present sample size relative to number of age classes suggests that the level of precision for

339 estimating maximum age was appropriate (Kritzer, Davies, \& Mapstone, 2001), but truncation of 
340 age structure cannot be discounted when sampling from historically harvested stocks. Ultimately,

341 estimates of total mortality derived in this study should be interpreted with caution.

342 Replacing data from Pohnpei with data from Guam in an otherwise Guam-specific

343 analysis of vulnerability, led to considerable improvements in fit for models linking life-history

344 traits with vulnerability to overexploitation. This strengthens the conclusion from Taylor et al.

345 (2014) that life-history traits are strong predictors of vulnerability to overexploitation in

346 parrotfishes. However, it also highlights the danger in, and fisheries implications of, borrowing

347 life-history data from other regions. Here, trait values between Pohnpei and Guam populations

348 did not differ greatly, but the direction of differences was generally consistent across traits. This

349 directionality was reflected in improved model fits because $H$. longiceps was among the most

350 vulnerable species, and trait values from Guam were, as predicted, generally greater than those

351 from Pohnpei. Contemporary stock assessment strategies for tropical fisheries rely on quality

352 biological information and region-specific information can remove much of the guess-work

353 involved in data-poor fisheries management (Newman et al., 2016; Prince et al., 2015).

\section{Conclusions}

Hipposcarus longiceps is a priority species in the Guam reef-associated commercial

fishery. By deriving detailed age-based and reproductive information for the exploited stock species and is directly applicable for fishery managers.

Acknowledgements 
363 The authors thank the Guam Biosampling Team for their immense efforts and T. T. Jones and D.

364 Kobayashi for comments on an earlier draft of the manuscript. Formal reviews by Jason Morton

365 and one anonymous reviewer improved the manuscript. All data used in this publication are from

366 https://inport.nmfs.noaa.gov/inport/item/5625.

367 
368

369

370

371

372

373

374

375

376

377

378

379

380

381

382

383

384

385

386

387

388

389

\section{References}

Abesamis RA, Green AL, Russ GR, Jadloc CR. 2014. The intrinsic vulnerability to fishing of coral reef fishes and their differential recovery in fishery closures. Reviews in Fish Biology and Fisheries 24:1033-1063. DOI: 10.1007/s11160-014-9362-x.

Adams PB. 1980. Life history patterns in marine fishes and their consequences for fisheries management. Fishery Bulletin 78:1-12.

Bellwood DR, Choat JH. 1989. A description of the juvenile phase colour patterns of 24 parrotfish specues (family Scaridae) from the Great Barrier Reef, Australia. Records of the Australian Museum 41:1-41.

Bellwood DR, Choat JH. 1990. A functional analysis of grazing in parrotfishes (family Scaridae): the ecological implications. Environmental Biology of Fishes 28:189-214. DOI: 10.1007/BF00751035.

Beverton RJH, Holt SJ. 1957. On the Dynamics of Exploited Fish Populations. London: Chapman and Hall.

Brown-Peterson NJ, Wyanski DM, Saborido-Rey F, Macewicz BJ, Lowerre-Barbieri SK. 2011. A standardized terminology for describing reproductive development in fishes. Marine and Coastal Fisheries 3:52-70. DOI: 10.1080/19425120.2011.555724.

Choat JH, Robertson DR. 2002. Age-based Studies. In: Sale PF, ed. Coral reef fishes: dynamics and diversity in a complex ecosystem. San Diego: Academic Press, 57-80.

Choat JH, Robbins WD, Clements KD. 2004. The trophic status of herbivorous fishes on coral reefs. II. Food processing modes and trophodynamics. Marine Biology 145:445-454. DOI: 10.1007/s00227-004-1341-7. 
390

391

392

393

394

395

396

397

398

399

400

401

402

403

404

405

406

407

408

409

410

411

412

Choat JH, Klanten OS, Van Herwerden L, Robertson DR, Clements KD. 2012. Patterns and processes in the evolutionary history of parrotfishes (Family Labridae). Biological Journal of the Linnean Society 107:529-557. DOI: 10.1111/j.1095-8312.2012.01959.x.

Colin PL. 2012. Longnose parrotfish - Hipposcarus longiceps. In: Sadovy de Mitcheson Y, Colin PL, eds. Reef Fish Spawning Aggregations: Biology, Research and Management. Dordrecht: Springer, 496-502.

Colin PL, Bell LJ. 1991. Aspects of the spawning of labrid and scarid fishes (Pisces:Labroidei) at Enewetak Atoll, Marshall Islands with notes on other families. Environmental Biology of Fishes 31:229-260. DOI: 10.1007/BF00000690.

Gust N. 2004. Variation in the population biology of protogynous coral reef fishes over tens of kilometers. Canadian Journal of Fisheries and Aquatic Science 61:205-218. DOI: 10.1139/f03-160.

Hamilton RJ, Adams S, Choat JH. 2008. Sexual development and reproductive demography of the green humphead parrotfish (Bolbometopon muricatum) in the Solomon Islands. Coral Reefs 27:153-163. DOI: 10.1007/s00338-007-0304-0.

Hoenig JM. 1983. Empirical use of longevity data to estimate mortality rates. Fishery Bulletin 82: 898-903.

Houk P, Rhodes K, Cuetos-Bueno J, Lindfield S, Fread V, McIlwain JL. 2012. Commercial coral-reef fisheries across Micronesia: A need for improving management. Coral Reefs 31:13-26. DOI: 10.1007/s00338-011-0826-3.

Kamikawa KT, Cruz E, Essington TE, Hospital J, Brodziak JKT, Branch TA. 2015. Lengthweight relationships for 85 fish species from Guam. Journal of Applied Ichthyology 31:1171-1174. DOI: 10.1111/jai.12877. 
413 Kerr AM. 1990. Chamorro fish names. Micronesica 23:93-118.

414 Kimura DK. 1980. Likelihood methods for the von Bertalanffy growth curve. Fishery Bulletin 415 $77: 765-776$

416 Kritzer JP, Davies CR, Mapstone BD. 2001. Characterizing fish populations: effects of sample 417 size and population structure on the precision of demographic parameter estimates. 418 Canadian Journal of Fisheries and Aquatic Science 58:1557-1568. DOI: 10.1139/f01-098. 419 Lindfield SJ, McIlwain JL, Harvey ES. 2014. Depth refuge and the impacts of SCUBA spearfishing on coral reef fishes. PLOS ONE 9:e92628. DOI:

422

423

424

425

426

427

428

429

430

431

432

433

434

435 10.1371/journal.pone.0092628.

Munday PL, White JW, Warner RR. 2006. A social basis for the development of primary males in a sex-changing fish. Proceedings of the Royal Society B: Biological Sciences 273:28452851. DOI: $10.1098 / \mathrm{rspb} .2006 .3666$.

Newman SJ, Williams AJ, Wakefield CB, Nicol SJ, Taylor BM, O’Malley JM. 2016. Review of the life history characteristics, ecology and fisheries for deep-water tropical demersal fish in the Indo-Pacific region. Reviews in Fish Biology and Fisheries 26:537-562. DOI: 10.1007/s11160-016-9442-1.

Prince J, Hordyk A, Valencia SR, Loneragan N, Sainsbury K. 2015. Revisiting the concept of Beverton-Holt life-history invariants with the aim of imforming data-poor fisheries assessment. ICES Journal of Marine Science 72:194-203. DOI: 10.1093/icesjms/fsu011.

Robertson DR, Reinboth R, Bruce RW. 1982. Gonochorism, protogynous sex-change and spawning in three Sparisomatine parrotfishes from the western Indian Ocean. Bulletin of Marine Science 32:868-879. 
436 Rhodes KL, Tupper MH, Wichilmel CB. 2008. Characterization and management of the

437

438

439

440

441

442

443

444

445

446

447

448

449

450

451

452

453

454

455

456

457 commercial sector of the Pohnpei coral reef fishery, Micronesia. Coral Reefs 27:443-454. DOI: $10.1007 / \mathrm{s} 00338-007-0331-\mathrm{x}$.

Sabetian A. 2010. Parrotfish fisheries and population dynamics: a case-study from Solomon Islands. PhD Thesis, James Cook University, Townsville, QLD, Australia.

Sadovy de Mitcheson Y, Liu M. 2008. Functional hermaphroditism in teleosts. Fish and Fisheries 9:1-43. DOI: 10.1111/j.1467-2979.2007.00266.x.

Sundberg M, Humphreys R, Lowe MK, Cruz E, Gourley J, Ochavillo D. 2015. Status of life history sampling conducted through the commercial fisheries bio-sampling programs in the Western Pacific Territories of American Samoa and Guam and in the Commonwealth of the Northern Mariana Islands. NOAA Administrative Report H-15-08, 56 pp. https://pifscwww.irc.noaa.gov/library/pubs/admin/PIFSC_Admin_Rep_15-08.pdf

Taylor BM. 2014. Drivers of protogynous sex change differ across spatial scales. Proceedings of the Royal Society B: Biological Sciences 281:20132423. DOI: 10.1098/rspb.2013.2423.

Taylor BM, Choat JH. 2014. Comparative demography of commercially important parrotfish species from Micronesia. Journal of Fish Biology 84:383-402. DOI: 10.1111/jfb.12294.

Taylor BM, Houk P, Russ GR, Choat JH. 2014. Life histories predict vulnerability to overexploitation in parrotfishes. Coral Reefs 33:869-878. DOI: 10.1007/s00338-014-11875.

Warner RR, Hoffman SG. 1980. Local population size as a determinant of mating system and sexual composition in two tropical marine fishes (Thalassoma spp). Evolution 34:508-518. DOI: $10.2307 / 2408220$. 
458 West G. 1990. Methods of assessing ovarian development in fishes: a review. Marine and

$459 \quad$ Freshwater Research 41:199-222. DOI: 10.1071/MF9900199.

460 


\section{Figure captions}

462 Figure 1. (a) Frequency of opaque edge deposition by month in transverse sections of

463 Hipposcarus longiceps otoliths plotted with sea surface temperature (satellite derived, Terra

464 MODIS database, 2010). Numbers associated with data points indicate sample sizes. (b)

465 Photomicrograph of a transverse section of a Hipposcarus longiceps otolith viewed with

466 transmitted light. Opaque annuli are denoted by rectangles.

467

468 Figure 2. (a) Sex-specific length- and (b) age-frequency distributions of sampled Hipposcarus

469 longiceps from Guam. Data points and linear regression line (with 95\% confidence limits) in (b)

470 represent the age-based catch curve $(y=m x+b)$ derived from natural log-transformed catch at

471 age values. Open circles indicate age classes considered not fully recruited to the fishery. The

472 curved line represents the expected proportion of individuals at age from the multinomial catch

473 curve with logistic selectivity.

474

475 Figure 3. Sex-specific patterns of growth, modelled using the von Bertalanffy growth function,

476 for Hipposcarus longiceps from Guam $(\mathrm{n}=265) . L_{\infty}$, asymptotic fork length; $K$, coefficient used

477 to describe the curvature of fish growth towards $L_{\infty}$. Inset, ellipses represent the $95 \%$ confidence

478 intervals surrounding estimates of $K$ and $L_{\infty}$ for each sex. Points within confidence ellipses

479 represent mean estimated values.

480

481

Figure 4. Photomicrograph of a histological section of a $370 \mathrm{~mm}$ specimen undergoing sexual

482 transition from a functionally mature female to a maturing male, demonstrating structural

483 characteristics of degenerative vitellogenic and primary oocytes (AVO, atretic vitellogenic 
484 oocyte; APO, atretic primary oocyte) in the presence of proliferating spermatogenic material

$485\left(1^{\circ} \mathrm{SC}\right.$, primary spermatocytes; $2^{\circ} \mathrm{SC}$, secondary spermatocytes).

486

487 Figure 5. Plots of (a) fork length and (b) age at 50\% sexual maturity, and (c) fork length at 50\% 488 sex change, along with associated logistic ogives describing the patterns of maturation and sex 489 change for female Hipposcarus longiceps from Guam. Numbers above sampling bins represent 490 respective sample sizes. Solid lines represent the best-fit models, dotted lines represent the 491 associated $95 \%$ confidence intervals.

492

493 Figure 6. Plots of raw gonadosomatic index values (left y-axis) for mature, active female 494 Hipposcarus longiceps $(\mathrm{n}=103)$ across $(\mathrm{a})$ calendar months and (b) lunar days. Solid lines 495 represent the proportion of mature females with the presence of post ovulatory follicles (POFs) and/or hydrated oocytes (right y-axis), indicating the recent or imminent occurrence of spawning. 


\section{Figure 1}

Figure 1

(a) Frequency of opaque edge deposition by month in transverse sections of Hipposcarus longiceps otoliths plotted with sea surface temperature (satellite derived, Terra MODIS database, 2010). Numbers associated with data points indicate sample sizes. (b) Photomicrograph of a transverse section of a Hipposcarus longiceps otolith viewed with transmitted light. Opaque annuli are denoted by rectangles. 


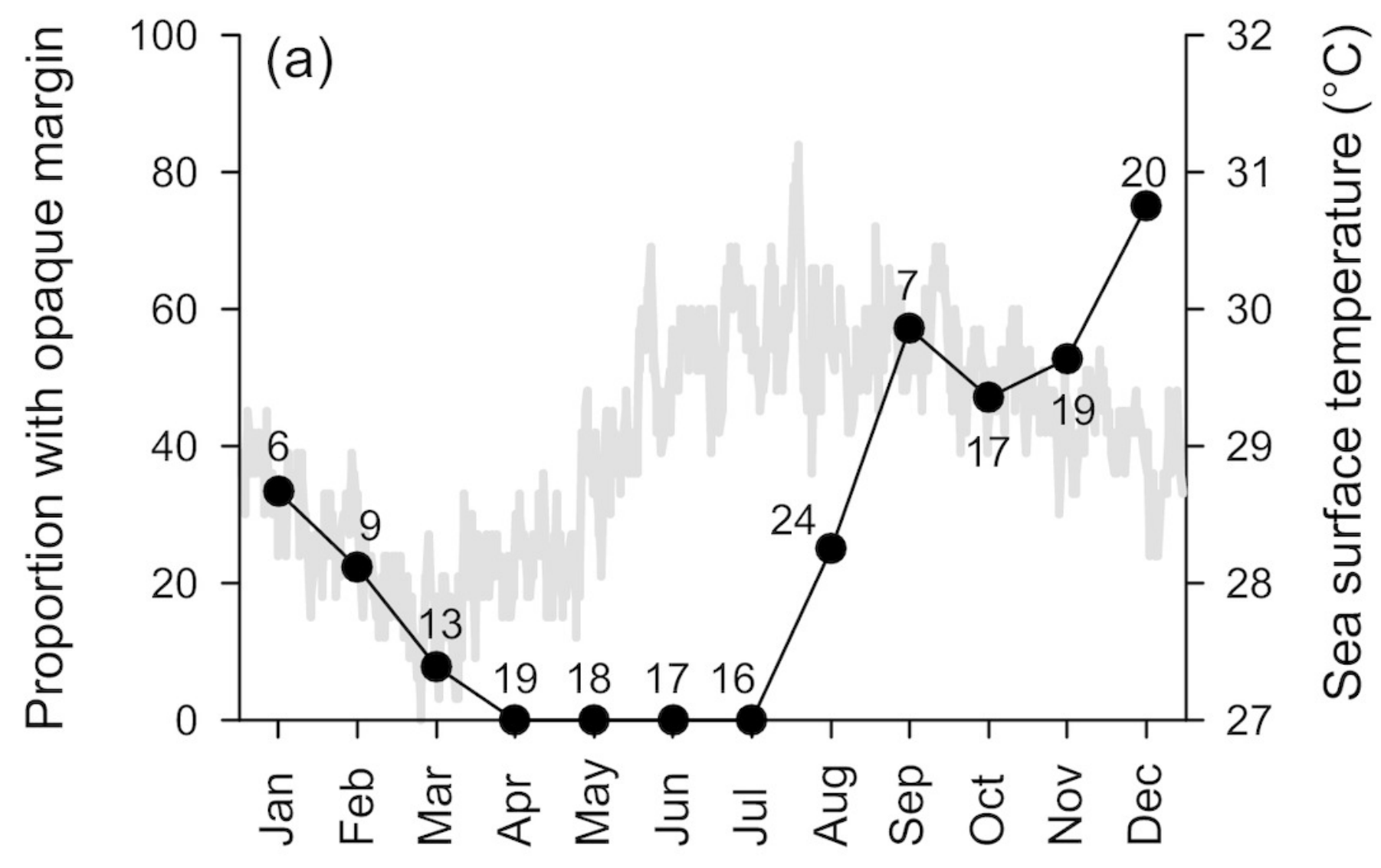

\section{(b)}




\section{Figure 2}

Figure 2

(a) Sex-specific length- and (b) age-frequency distributions of sampled Hipposcarus longiceps from Guam. Data points and linear regression line (with 95\% confidence limits) in (b) represent the age-based catch curve $(y=m x+b)$ derived from natural log-transformed catch at age values. Open circles indicate age classes considered not fully recruited to the fishery. The curved line represents the expected proportion of individuals at age from the multinomial catch curve with logistic selectivity.
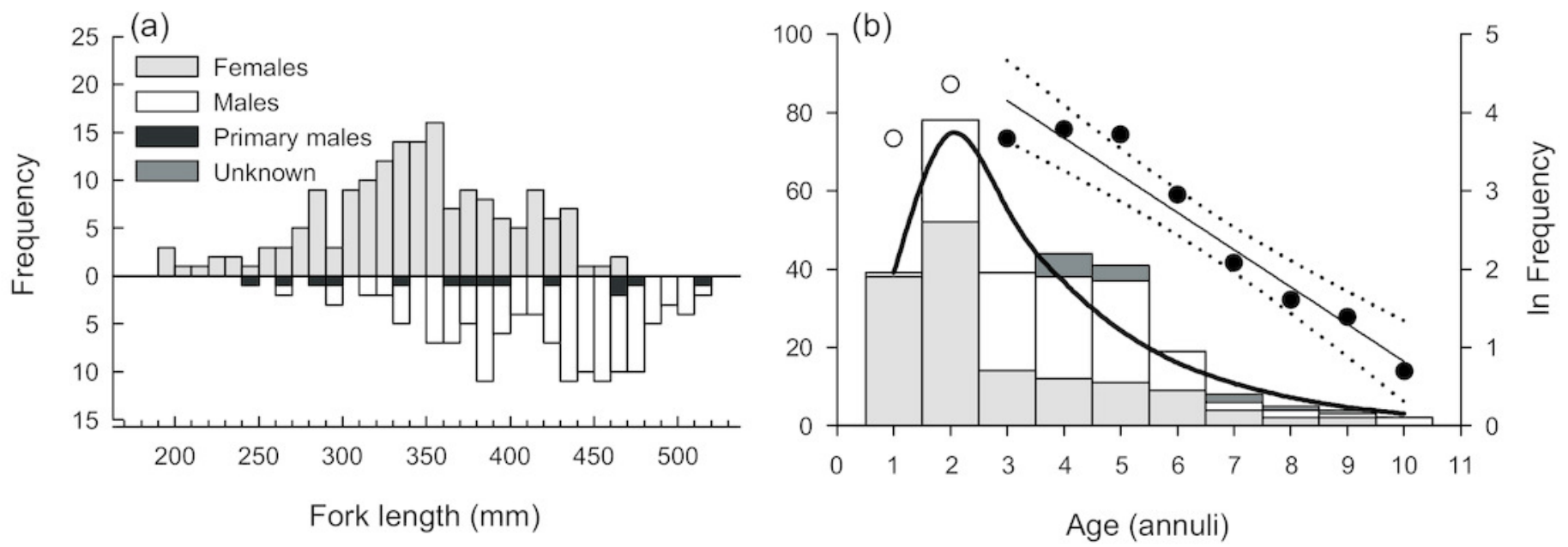


\section{Figure 3}

Figure 3

Sex-specific patterns of growth, modelled using the von Bertalanffy growth function, for

Hipposcarus longiceps from Guam $(n=265)$. $L_{\infty}$, asymptotic fork length; $K$, coefficient used to describe the curvature of fish growth towards $L_{\infty}$. Inset, ellipses represent the $95 \%$ confidence intervals surrounding estimates of $K$ and $L_{\infty}$ for each sex. Points within confidence ellipses represent mean estimated values. 


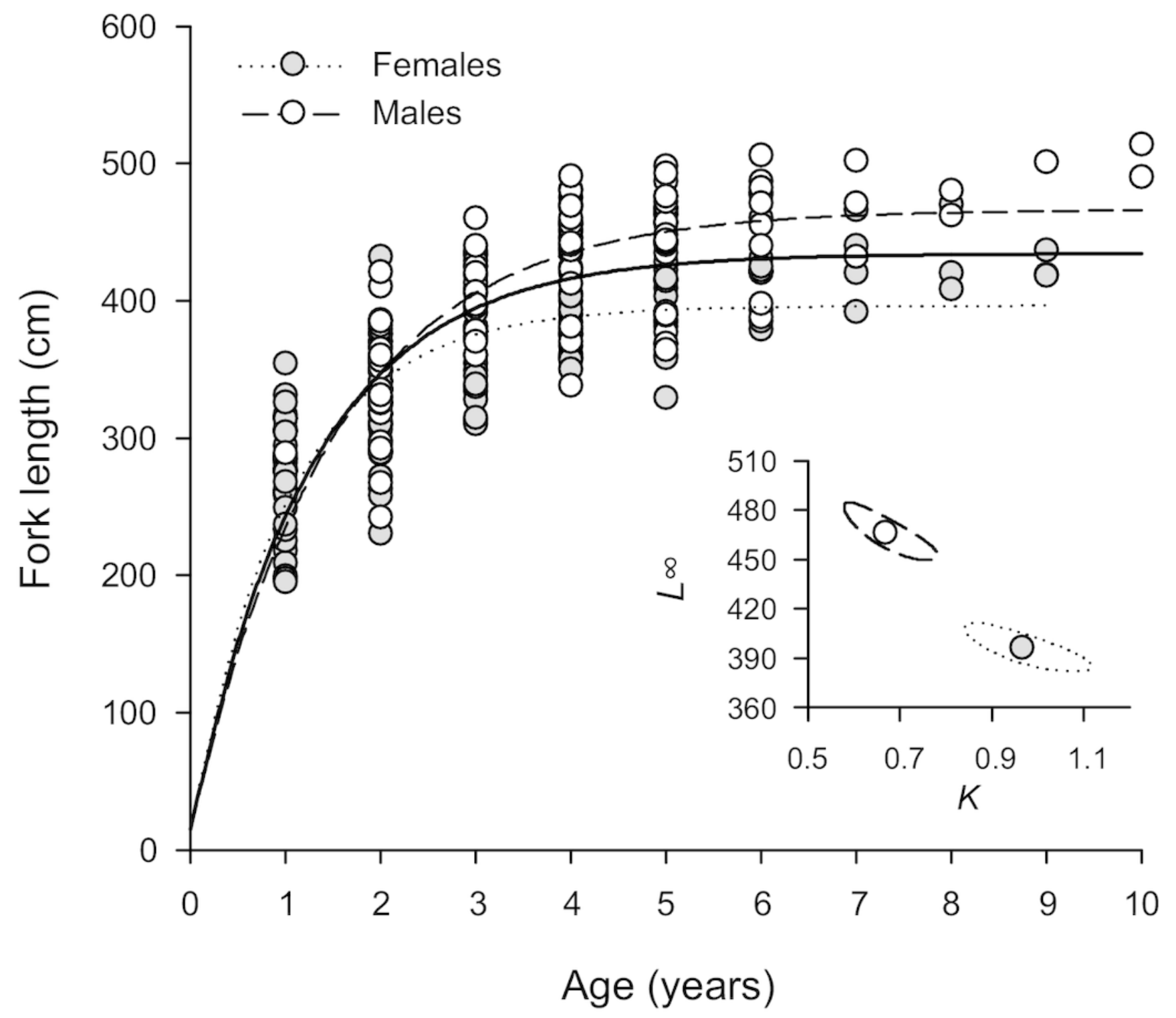




\section{Figure 4}

Figure 4

Photomicrograph of a histological section of a $370 \mathrm{~mm}$ specimen undergoing sexual transition from a functionally mature female to a maturing male, demonstrating structural characteristics of degenerative vitellogenic and primary oocytes (AVO, atretic vitellogenic oocyte; APO, atretic primary oocyte) in the presence of proliferating spermatogenic material ( $1^{\circ} \mathrm{SC}$, primary spermatocytes; $2^{\circ} \mathrm{SC}$, secondary spermatocytes).

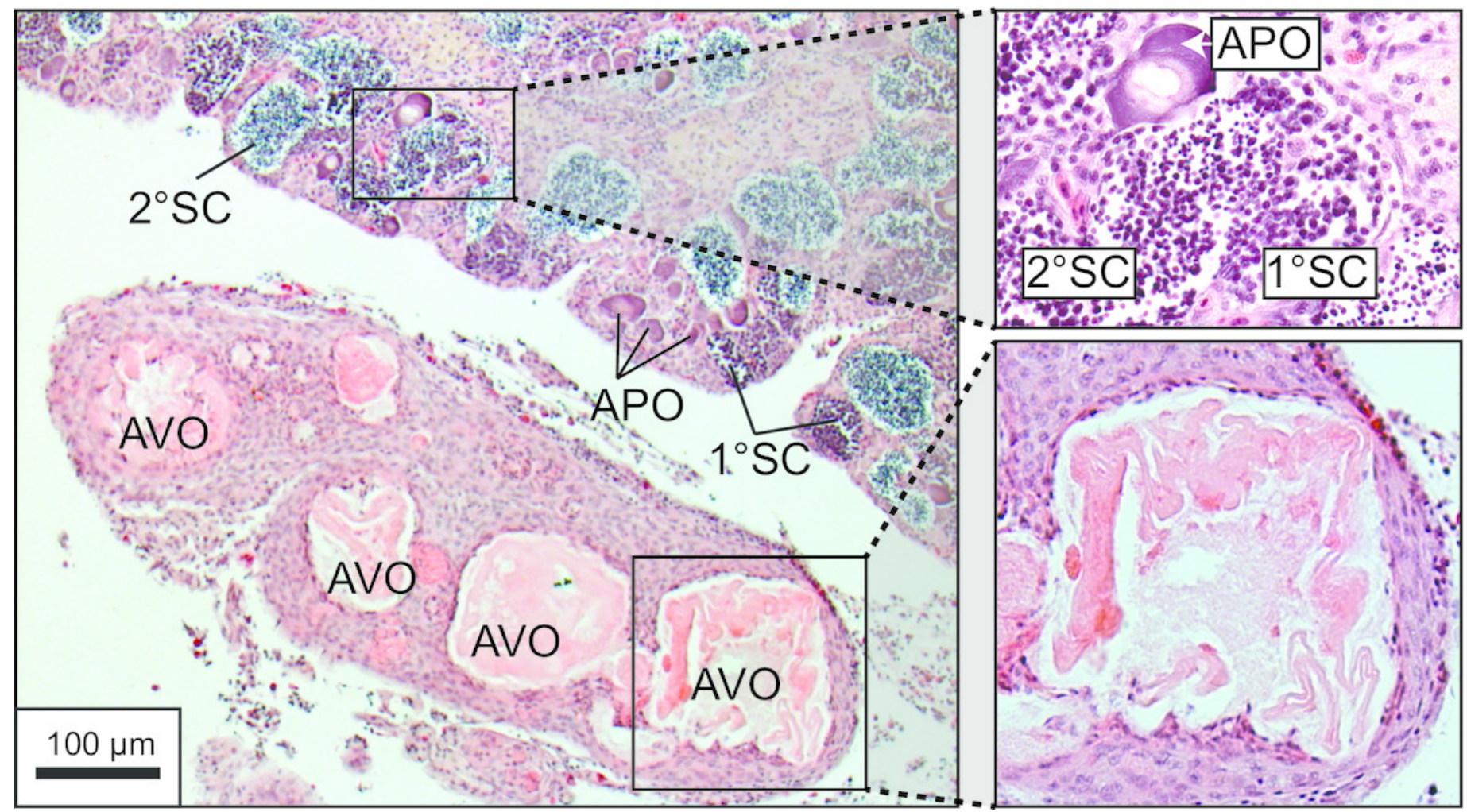


Figure 5

Figure 5

Plots of (a) fork length and (b) age at $50 \%$ sexual maturity, and (c) fork length at $50 \%$ sex change, along with associated logistic ogives describing the patterns of maturation and sex change for female Hipposcarus longiceps from Guam. Numbers above sampling bins represent respective sample sizes. Solid lines represent the best-fit models, dotted lines represent the associated $95 \%$ confidence intervals.
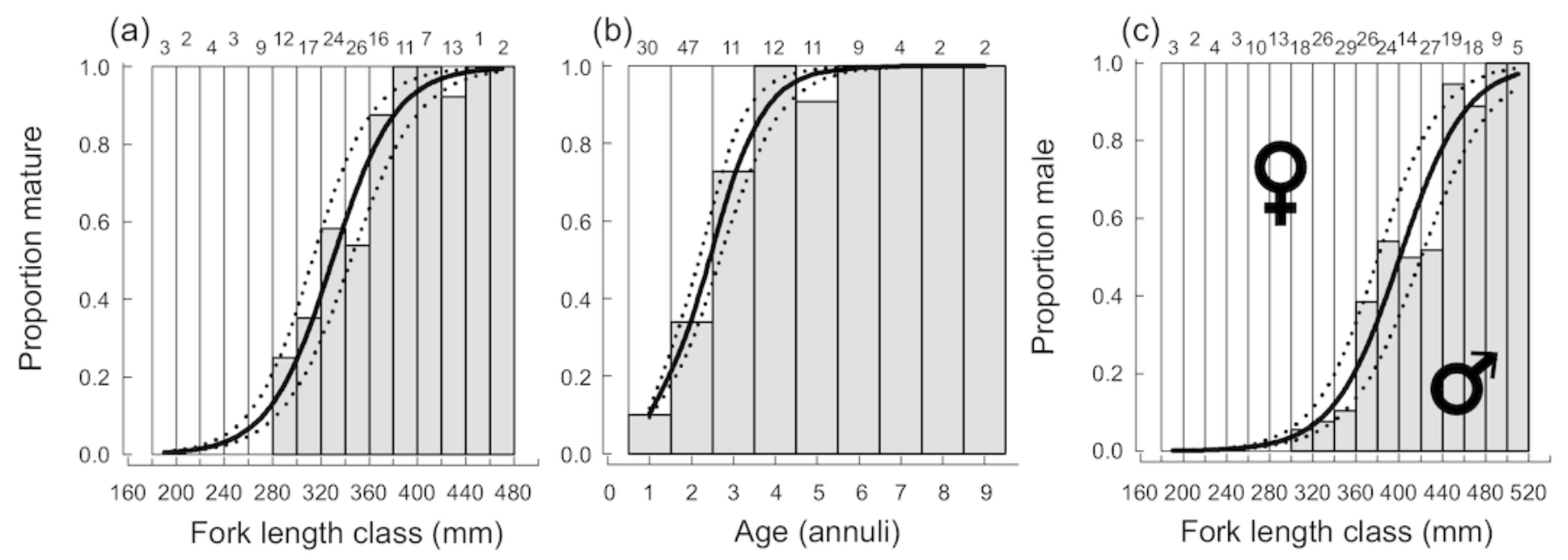
Figure 6

Figure 6

Plots of raw gonadosomatic index values (left y-axis) for mature, active female Hipposcarus longiceps ( $n=103$ ) across (a) calendar months and (b) lunar days. Solid lines represent the proportion of mature females with the presence of post ovulatory follicles (POFs) and/or hydrated oocytes (right y-axis), indicating the recent or imminent occurrence of spawning.

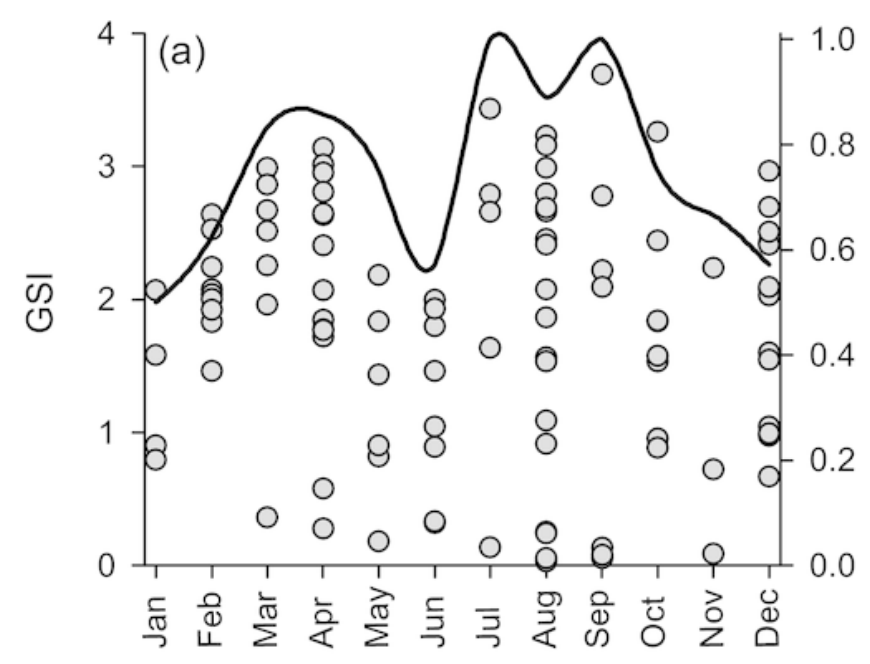

Calendar month

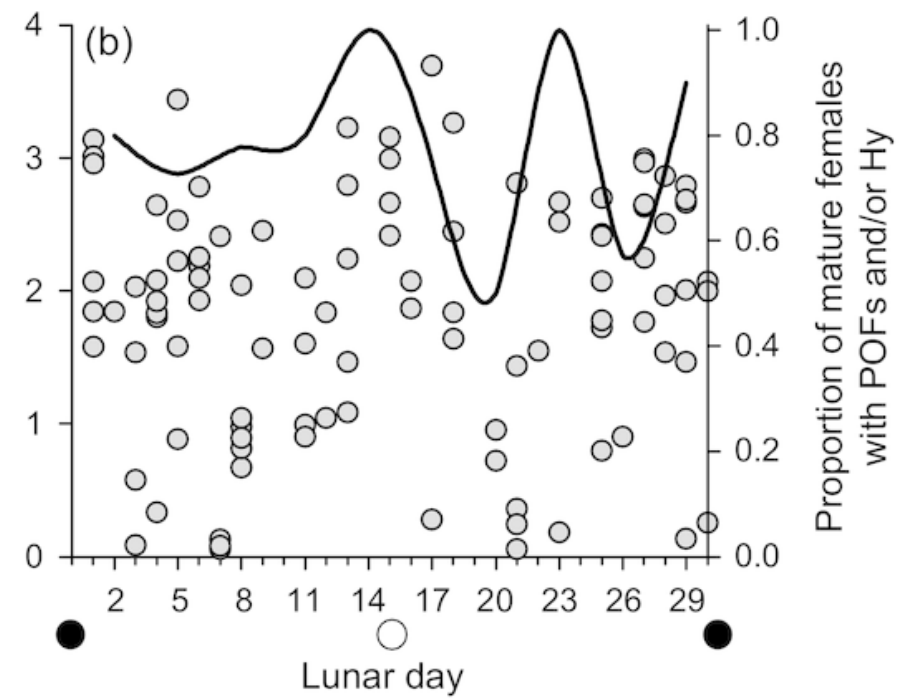




\section{Table $\mathbf{1}$ (on next page)}

Table 1

Summary of life-history trait estimates for Hipposcarus longiceps from Guam. Associated 95 $\%$ confidence intervals are presented in parentheses where appropriate. 
1 Table 1. Summary of life-history trait estimates for Hipposcarus longiceps from Guam.

2 Associated $95 \%$ confidence intervals are presented in parentheses where appropriate.

\begin{tabular}{lccc}
\hline Trait & Females & Males & Combined \\
\hline$L_{\infty}(\mathrm{mm})$ & $396(382-411)$ & $466(450-485)$ & $434(422-446)$ \\
$K\left(\mathrm{yr}^{-1}\right)$ & $0.97(0.84-1.12)$ & $0.67(0.58-0.78)$ & $0.79(0.71-0.87)$ \\
$t_{0}(\mathrm{yr})$ & -0.04 & -0.05 & -0.04 \\
$\mathrm{n}$ & 144 & 121 & 279 \\
$L_{50}(\mathrm{~mm})$ & $329(313-345)$ & - & - \\
$t_{50}(\mathrm{yr})$ & $2.4(2.2-2.7)$ & - & - \\
$L_{\Delta 50}(\mathrm{~mm})$ & - & - & $401(381-420)$ \\
$Z\left(\mathrm{yr}^{-1}\right)$ linear & - & - & $0.476(0.375-0.577)$ \\
$Z\left(\mathrm{yr}^{-1}\right)$ multinomial & - & - & $0.402(0.377-0.489)$ \\
\hline
\end{tabular}

3

$4 \quad L_{\infty}$, asymptotic length; $K$, growth coefficient; $t_{0}$, hypothetical age when length equals zero; $\mathrm{n}$, sample size;

$5 L_{50}$, length at $50 \%$ sexual maturity; $t_{50}$, age at $50 \%$ sexual maturity; $L_{\Delta 50}$, length at $50 \%$ sex change; $Z$

6 linear, instantaneous total mortality rate estimated from the linear age-based catch curve; $Z$ multinomial,

7 instantaneous total mortality rate estimated from the logistic multinomial catch curve.

8 